\title{
Understanding the sensitivity of numerical slope stability analyses to geotechnical and other input parameters
}

\author{
DR Wines Itasca Australia Pty Ltd, Australia
}

\begin{abstract}
Most geotechnical inputs required to perform a slope stability analysis involve some degree of uncertainty (i.e. the exact value or variability for these inputs is not known). Sensitivity analyses are often performed to assess the influence of parameter variability on the predicted slope behaviour. It is therefore valuable to understand which inputs are most important for a slope stability analysis, and where efforts should be focused with respect to field and laboratory investigations and sensitivity analyses.

Three-dimensional numerical slope stability analyses have been performed to assess the influence of several inputs on the predicted slope behaviour. Analyses have been run for different slope failure mechanisms, including rotational, wedge and toppling failures. Inputs that have been assessed include the rock mass properties, the discontinuity properties, the in situ stresses and the pore pressures.

The analyses indicate that all of the inputs have some influence on the predicted slope behaviour. However, the adopted rock density, strength parameters (for the rock mass and discontinuities) and pore pressures have the most significant influence on the predicted Factors of Safety. This indicates that investigation of the rock density, strength properties and pore pressures should be prioritised when performing slope stability analyses. In a hard rock environment, development of a reliable structural model is also critical.
\end{abstract}

Keywords: numerical modelling, slope stability, Factor of Safety, sensitivity

\section{Introduction}

Numerical models are routinely used to assess the stability of natural and man-made slopes. These analyses require several inputs, some of which are known (e.g. the existing slope geometry), but most of which need to be estimated (e.g. the material strength, in situ stresses and pore pressures). All inputs that need to be estimated involve some degree of uncertainty and sensitivity analyses are often performed to assess the influence of parameter variability on the predicted slope behaviour. It is therefore valuable to understand which inputs are most important for a slope stability analysis, and therefore where efforts should be focused with respect to field and laboratory investigations and sensitivity analyses.

Three-dimensional numerical slope stability analyses have been performed to assess the influence of several inputs on the predicted slope behaviour. In particular, the impact of various inputs on the predicted Factor of Safety (FoS) is assessed, because the FoS is often the main modelling outcome used to assess the acceptability of an existing slope or a planned slope design. The effect of different inputs on the resulting model displacements is also assessed.

Hoek \& Bray (1974) discuss four main types of failures in slopes, as illustrated in Figure 1. The modelling performed in this paper aims to assess the circular, wedge and toppling failure mechanisms. Inputs that have been assessed include the rock mass properties, the discontinuity properties, the in situ stresses and the pore pressures.

The numerical analyses have been performed using the three-dimensional distinct element code 3DEC (Itasca Consulting Group 2018). A significant number of structures can be explicitly-defined in a 3DEC model, and the material in between those structures (i.e. the rock mass) is represented as a mesh of finite difference elements. Therefore, 3DEC provides an appropriate tool to analyse the effects of the adopted properties for 
both explicit structures and the 'rock mass' on predicted stability. The effects of in situ stresses and pore pressures can also be analysed.
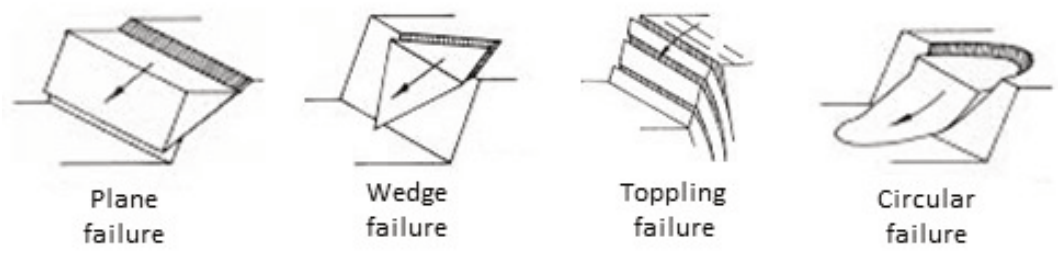

Figure 1 Four main types of failures in slopes (after Hoek \& Bray 1974)

The results of this study are meaningful to both rock and soil slopes. However, it is noted that the selected model inputs are based on typical conditions that may be encountered in a hard rock open pit environment. The results and conclusions presented in this paper are relevant to the adopted slope height and angle and the adopted modelling methodology. If a higher or steeper slope was to be analysed, or if different constitutive models were adopted, the results and conclusions may differ.

\section{$2 \quad$ Summary of modelling scenarios and results}

Three separate 3DEC models have been constructed and run to analyse rock mass (circular/rotational), wedge and toppling failure. Geotechnical parameters and other model inputs that have been assessed include the following:

- Rock density is assessed for all three failure modes.

- Rock mass properties: Young's modulus, Poisson's ratio, cohesion, friction angle, tensile strength and dilation angle have been assessed for the rock mass and toppling failure modes (but not the wedge failure because this is structurally-controlled, without any need for rock mass failure). Other rock mass parameters have also been assessed separately for the rock mass failure mode only, including uniaxial compressive strength (UCS), Geological Strength Index (GSI), $m_{i}, D$ factor, bulk and shear modulus, and selection of an upper confining stress when estimating the rock mass shear strength.

- Structure properties: Normal and shear stiffness, cohesion, friction angle, tensile strength and dilation angle have been assessed for the wedge and toppling failure modes (but not the rock mass failure, because structure is not explicitly represented in this model).

- In situ stresses: For all three failure modes, models have been run with different pre-mining in situ stress assumptions. This includes several horizontal to vertical stress ratios, and with different horizontal stress magnitudes in different directions.

- Pore pressures: The effect of pore pressure has been assessed for all three failure modes. This has been performed by creating phreatic surfaces at different distances behind the slope face and assuming hydrostatic conditions below.

- Model zone (or element) size: The effect of the selected model zone or element size has also been assessed for the rock mass and toppling failure modes.

The impact of the various inputs on the predicted FoS and displacements was assessed. Models were run with 'base case' values for all parameters, and sensitivity analyses were performed by varying one parameter/input at a time. In most cases, the base case values were decreased by $50 \%$ and increased by $50 \%$. In some cases, the base case value was zero (e.g. the joint tensile strength and dilation angle). In these cases, sensitivity analyses were performed by running models with selected non-zero values.

A summary of the results is provided in Table 1 (FoS) and Table 2 (cumulative displacement, monitored at a point on the crest). These tables show the influence of the geotechnical parameters listed above. The influence of other factors such as the in situ stresses and pore pressures are presented and discussed in the 
sections below. The geotechnical parameters that have the most effect on the FoS are the rock density and the shear strength of the rock mass and structures. The parameters that have the most effect on the displacements are the rock density and the rock mass Young's modulus and Poisson's ratio. The shear strength of the rock mass and structures also have some effect on displacement. As discussed in the sections below, the pore pressures, in situ stresses and model zone size can also have a significant effect on the model behaviour (both FoS and displacement).

Table 1 Summary of Factor of Safety (FoS) from selected models with varied inputs

\begin{tabular}{|c|c|c|c|c|c|c|c|c|c|c|c|c|c|c|c|}
\hline \multirow[b]{2}{*}{ Parameter } & \multicolumn{5}{|c|}{ Rock mass failure } & \multicolumn{5}{|c|}{ Wedge failure } & \multicolumn{5}{|c|}{ Toppling failure } \\
\hline & 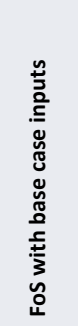 & 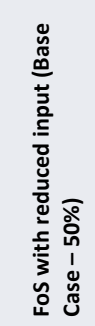 & 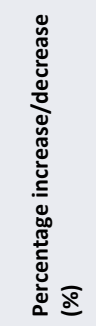 & 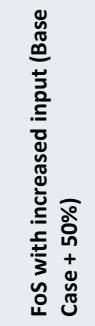 & 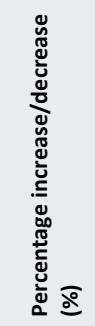 & 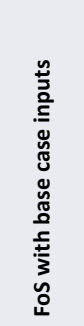 & 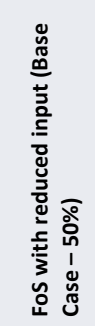 & 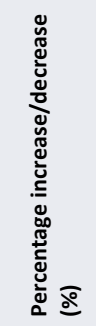 & 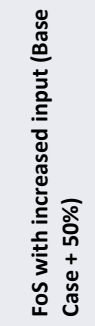 & 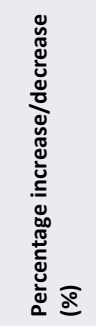 & 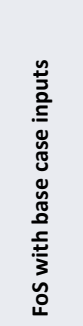 & 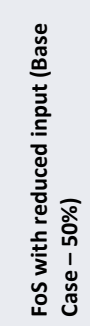 & 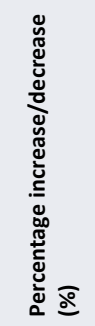 & 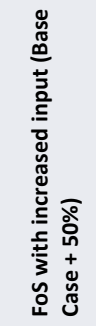 & 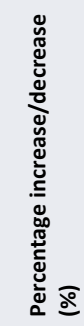 \\
\hline Density & 1.55 & 2.18 & $+41 \%$ & 1.29 & $-17 \%$ & 1.34 & 1.34 & $0 \%$ & 1.34 & $0 \%$ & 1.37 & 2.23 & $+63 \%$ & 1.08 & $-21 \%$ \\
\hline $\begin{array}{l}\text { Young's modulus } \\
\text { (rock mass) }\end{array}$ & 1.55 & 1.54 & $-1 \%$ & 1.57 & $+1 \%$ & - & - & - & - & - & 1.37 & 1.35 & $-1 \%$ & 1.37 & $0 \%$ \\
\hline $\begin{array}{l}\text { Poisson's ratio } \\
\text { (rock mass) }\end{array}$ & 1.55 & 1.55 & $0 \%$ & 1.56 & $+1 \%$ & - & - & - & - & - & 1.37 & 1.34 & $-2 \%$ & 1.40 & $+2 \%$ \\
\hline $\begin{array}{l}\text { Bulk modulus } \\
\text { (rock mass) }\end{array}$ & 1.55 & 1.57 & $+1 \%$ & 1.52 & $-2 \%$ & - & - & - & - & - & - & - & - & - & - \\
\hline $\begin{array}{l}\text { Shear modulus } \\
\text { (rock mass) }\end{array}$ & 1.55 & 1.55 & $0 \%$ & 1.55 & $0 \%$ & - & - & - & - & - & - & - & - & - & - \\
\hline Cohesion (rock mass) & 1.55 & 1.21 & $-22 \%$ & 1.89 & $+22 \%$ & - & - & - & - & - & 1.37 & 1.10 & $-20 \%$ & 1.41 & $+3 \%$ \\
\hline $\begin{array}{l}\text { Friction angle } \\
\text { (rock mass) }\end{array}$ & 1.55 & 0.99 & $-36 \%$ & 2.30 & $+48 \%$ & - & - & - & - & - & 1.37 & 1.15 & $-16 \%$ & 1.43 & $+4 \%$ \\
\hline $\begin{array}{l}\text { Tensile strength } \\
\text { (rock mass) }\end{array}$ & 1.55 & 1.54 & $-1 \%$ & 1.56 & $+1 \%$ & - & - & - & - & - & 1.37 & 1.32 & $-4 \%$ & 1.49 & $+9 \%$ \\
\hline $\begin{array}{l}\text { Dilation angle } \\
\text { (rock mass) }\end{array}$ & 1.55 & 1.55 & $0 \%$ & 1.54 & $-1 \%$ & - & - & - & - & - & 1.37 & 1.37 & $0 \%$ & 1.37 & $0 \%$ \\
\hline $\begin{array}{l}\text { Uniaxial compressive } \\
\text { strength }\end{array}$ & 1.55 & 1.23 & $-21 \%$ & 1.79 & $+15 \%$ & - & - & - & - & - & - & - & - & - & - \\
\hline $\begin{array}{l}\text { Geological Strength } \\
\text { Index }\end{array}$ & 1.55 & 0.93 & $-40 \%$ & 3.07 & $+98 \%$ & - & - & - & - & - & - & - & - & - & - \\
\hline$m_{i}$ & 1.55 & 1.28 & $-17 \%$ & 1.71 & $+10 \%$ & - & - & - & - & - & - & - & - & - & - \\
\hline Joint normal stiffness & - & - & - & - & - & 1.34 & 1.34 & $0 \%$ & 1.34 & $0 \%$ & 1.37 & 1.37 & $0 \%$ & 1.37 & $0 \%$ \\
\hline Joint shear stiffness & - & - & - & - & - & 1.34 & 1.35 & $+1 \%$ & 1.34 & $0 \%$ & 1.37 & 1.36 & $-1 \%$ & 1.37 & $0 \%$ \\
\hline Joint cohesion* & - & - & - & - & - & 1.68 & 1.52 & $\overline{10 \%}$ & 1.84 & $+10 \%$ & 1.37 & 0.98 & $-28 \%$ & 1.56 & $+14 \%$ \\
\hline Joint friction angle & - & - & - & - & - & 1.34 & 1.05 & $-\overline{22 \%}$ & 2.41 & $+80 \%$ & 1.37 & 1.09 & $-20 \%$ & 1.54 & $+12 \%$ \\
\hline $\begin{array}{l}\text { Joint tensile } \\
\text { strength* }\end{array}$ & - & - & - & - & - & 1.34 & 1.34 & $0 \%$ & 1.34 & $0 \%$ & 1.37 & 1.34 & $-2 \%$ & 1.37 & $0 \%$ \\
\hline Joint dilation angle* & - & - & - & - & - & 1.34 & 1.34 & $0 \%$ & 1.34 & $0 \%$ & 1.35 & 1.35 & $0 \%$ & 1.35 & $0 \%$ \\
\hline
\end{tabular}


Table 2 Summary of displacement (in $\mathrm{mm}$ ) from selected models with varied inputs

\begin{tabular}{|c|c|c|c|c|c|c|c|c|c|c|c|c|c|c|c|}
\hline \multirow[b]{2}{*}{ Parameter } & \multicolumn{5}{|c|}{ Rock mass failure } & \multicolumn{5}{|c|}{ Wedge failure } & \multicolumn{5}{|c|}{ Toppling failure } \\
\hline & 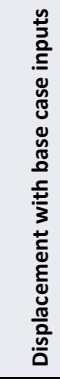 & 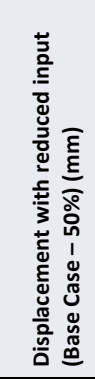 & 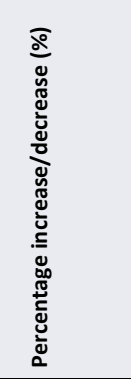 & 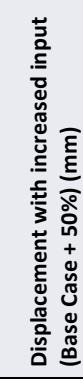 & 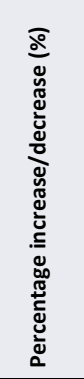 & 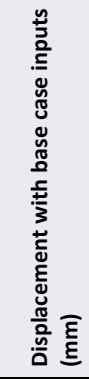 & 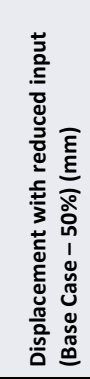 & 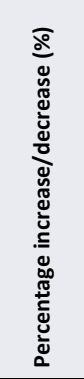 & 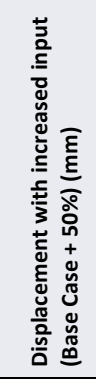 & 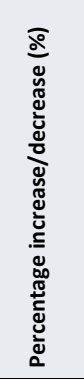 & 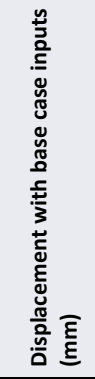 & 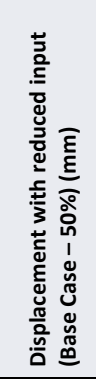 & 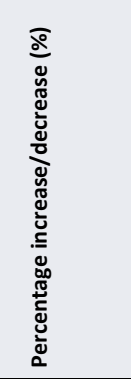 & 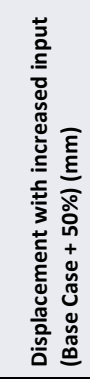 & 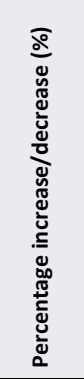 \\
\hline Density & 37 & 18 & $-51 \%$ & 58 & $+57 \%$ & 3.7 & 1.0 & $-73 \%$ & 5.6 & $+51 \%$ & 10 & 4 & $-60 \%$ & 17 & $+70 \%$ \\
\hline $\begin{array}{l}\text { Young's } \\
\text { modulus } \\
\text { (rock mass) }\end{array}$ & 37 & 74 & $+100 \%$ & 25 & $-32 \%$ & - & - & - & - & - & 10 & 19 & $+90 \%$ & 7 & $-30 \%$ \\
\hline $\begin{array}{l}\text { Poisson's } \\
\text { ratio } \\
\text { (rock mass) }\end{array}$ & 37 & 44 & $+19 \%$ & 32 & $-14 \%$ & - & - & - & - & - & 10 & 10 & $0 \%$ & 10 & $0 \%$ \\
\hline $\begin{array}{l}\text { Bulk modulus } \\
\text { (rock mass) }\end{array}$ & 37 & 53 & $+43 \%$ & 32 & $-14 \%$ & - & - & - & - & - & - & - & - & - & - \\
\hline $\begin{array}{l}\text { Shear } \\
\text { modulus } \\
\text { (rock mass) }\end{array}$ & 37 & 59 & $+59 \%$ & 31 & $-16 \%$ & - & - & - & - & - & - & - & - & - & - \\
\hline $\begin{array}{l}\text { Cohesion } \\
\text { (rock mass) }\end{array}$ & 37 & 40 & $+8 \%$ & 37 & $0 \%$ & - & - & - & - & - & 10 & 11 & $+10 \%$ & 10 & $0 \%$ \\
\hline $\begin{array}{l}\text { Friction angle } \\
\text { (rock mass) }\end{array}$ & 37 & $>100^{\wedge}$ & $>+100 \%^{\wedge}$ & 36 & $-3 \%$ & - & - & - & - & - & 10 & 12 & $+20 \%$ & 10 & $0 \%$ \\
\hline $\begin{array}{l}\text { Tensile } \\
\text { strength } \\
\text { (rock mass) }\end{array}$ & 37 & 38 & $+3 \%$ & 37 & $0 \%$ & - & - & - & - & - & 10 & 10 & $0 \%$ & 10 & $0 \%$ \\
\hline $\begin{array}{l}\text { Dilation } \\
\text { angle (rock } \\
\text { mass) }\end{array}$ & 37 & 37 & $0 \%$ & 37 & $0 \%$ & - & - & - & - & - & 10 & 10 & $0 \%$ & 10 & $0 \%$ \\
\hline $\begin{array}{l}\text { Uniaxial } \\
\text { compressive } \\
\text { strength }\end{array}$ & 37 & 40 & $+8 \%$ & 37 & $0 \%$ & - & - & - & - & - & - & - & - & - & - \\
\hline $\begin{array}{l}\text { Geological } \\
\text { Strength } \\
\text { Index }\end{array}$ & 37 & $>100^{\wedge}$ & $>+100 \% \wedge$ & 10 & $-73 \%$ & - & - & - & - & - & - & - & - & - & - \\
\hline$m_{i}$ & 37 & 39 & $+5 \%$ & 37 & $0 \%$ & - & - & - & - & - & - & - & - & - & - \\
\hline $\begin{array}{l}\text { Joint normal } \\
\text { stiffness }\end{array}$ & - & - & - & - & - & 3.7 & 3.7 & $0 \%$ & 3.7 & $0 \%$ & 10 & 10 & $0 \%$ & 10 & $0 \%$ \\
\hline $\begin{array}{l}\text { Joint shear } \\
\text { stiffness }\end{array}$ & - & - & - & - & - & 3.7 & 3.7 & $0 \%$ & 3.7 & $0 \%$ & 10 & 11 & $+10 \%$ & 10 & $0 \%$ \\
\hline $\begin{array}{l}\text { Joint } \\
\text { cohesion* }\end{array}$ & - & - & - & - & - & 3.7 & 3.7 & $0 \%$ & 3.7 & $0 \%$ & 10 & $>50^{\wedge}$ & $>+100 \%^{\wedge}$ & 10 & $0 \%$ \\
\hline $\begin{array}{l}\text { Joint friction } \\
\text { angle }\end{array}$ & - & - & - & - & - & 3.7 & 3.7 & $0 \%$ & 3.7 & $0 \%$ & 10 & 12 & $+20 \%$ & 10 & $0 \%$ \\
\hline $\begin{array}{l}\text { Joint tensile } \\
\text { strength* }\end{array}$ & - & - & - & - & - & 3.7 & 3.7 & $0 \%$ & 3.7 & $0 \%$ & 10 & 10 & $0 \%$ & 10 & $0 \%$ \\
\hline $\begin{array}{l}\text { Joint dilation } \\
\text { angle* }\end{array}$ & - & - & - & - & - & 3.7 & 3.7 & $0 \%$ & 3.7 & $0 \%$ & 10 & 10 & $0 \%$ & 10 & $0 \%$ \\
\hline
\end{tabular}

* In these cases, the base case values were zero, therefore another (non-zero) value is taken as the 'central' point.

^ Slope failure occurs in these cases, hence the high displacements. The displacements would keep increasing if the models were run for longer. 


\section{$3 \quad$ Modelling methodology}

Model inputs were selected to match conditions typically encountered in hard rock open pits. The slope height and angle are both similar to existing inter-ramp slopes, while the rock mass properties and in situ stresses are similar to those encountered by the author at exiting hard rock open pits.

\subsection{Model geometry}

The model used to assess rock mass failure has been constructed to analyse a $100 \mathrm{~m}$ high slope with a $60^{\circ}$ overall slope angle (Figure 2). The slope is planar (i.e. no benches or slope curvature are included). This model does not include any explicit structures, therefore failure can only occur through the continuum (represented by $3 D E C$ finite difference zones). The zone size in the base case model is around $5 \mathrm{~m}$ in the vicinity of the slope.

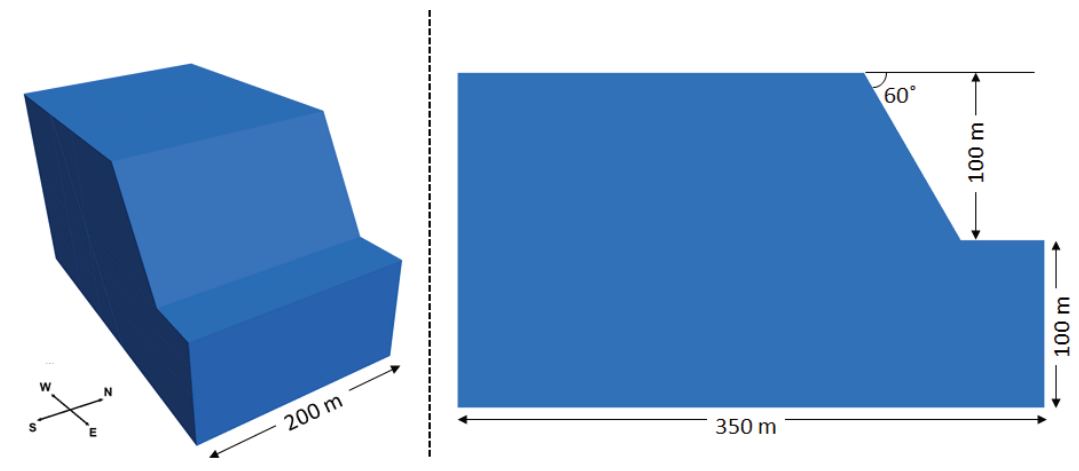

Figure 2 3DEC model used to analyse rock mass failure

The model used to assess wedge failure has been constructed to analyse a $30 \mathrm{~m}$ high slope with a $65^{\circ}$ overall slope angle (Figure 3). The slope is planar (i.e. no benches or slope curvature are included). Two structures are explicitly-defined in the model to create a wedge. The dip/dip direction of the two structures is $50^{\circ} / 36^{\circ}$ and $50^{\circ} / 144^{\circ}$. This results in a wedge that is around $26.5 \mathrm{~m}$ high. The dip of the intersection between the two structures is around $35^{\circ}$.

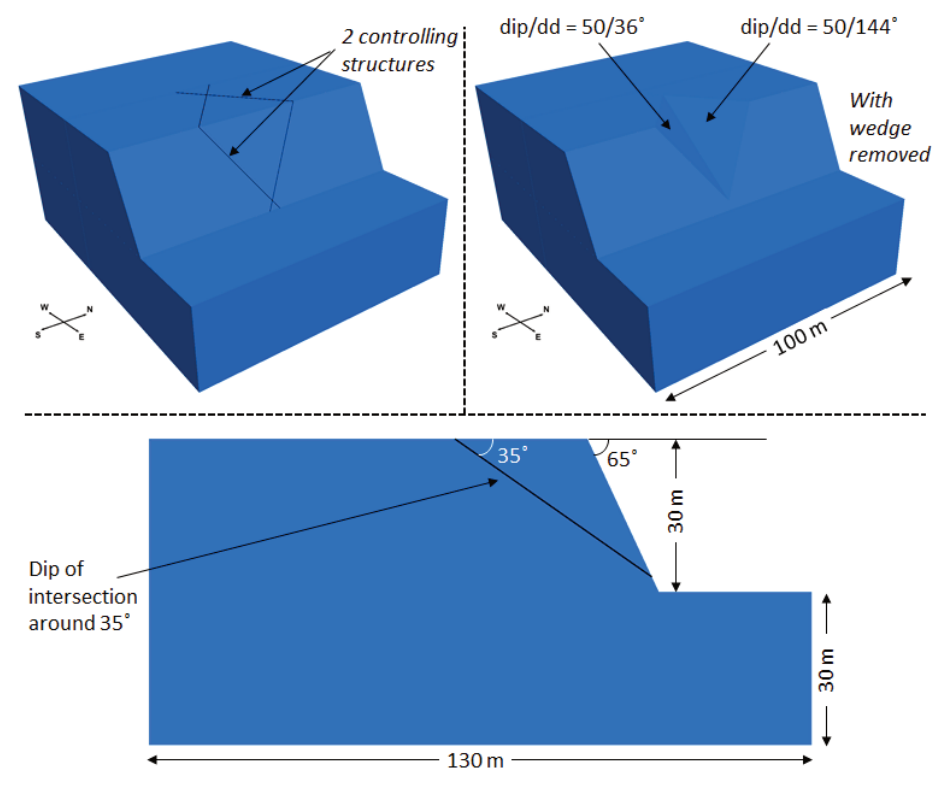

Figure 3 3DEC model used to analyse wedge failure

The model used to assess toppling failure has been constructed to analyse a $50 \mathrm{~m}$ high slope with a $75^{\circ}$ overall slope angle (Figure 4). The slope is planar (i.e. no benches or slope curvature are included). Continuous structures are explicitly-defined in the model dipping at $80^{\circ}$ into the slope with a spacing of $4 \mathrm{~m}$. When 
analysing flexural toppling, Lorig et al. (2009) recommend that a minimum of four zones across the rock column is usually required. Therefore, a $1 \mathrm{~m}$ zone size has been used in the area of interest, resulting in four zones across each column.

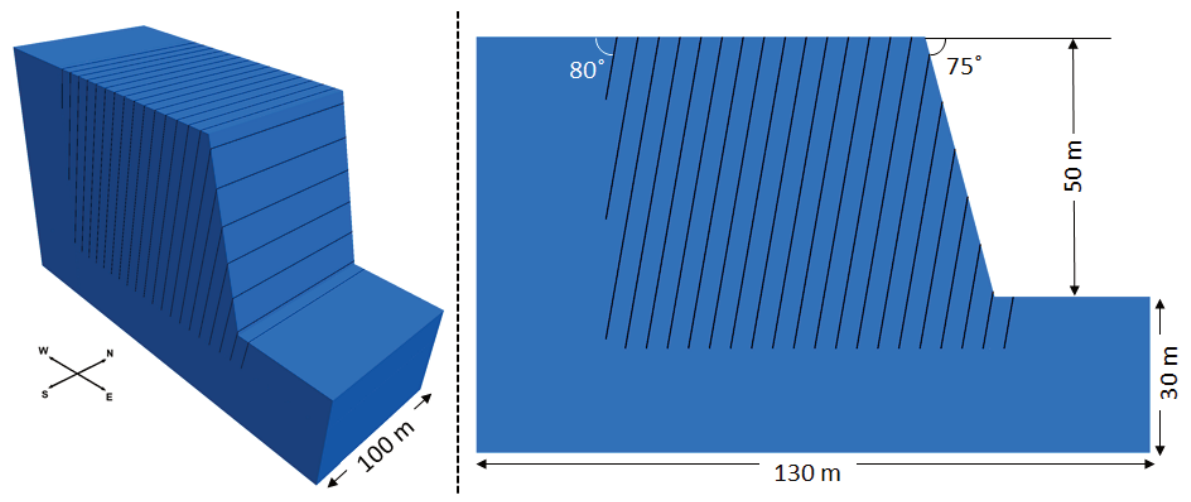

Figure 4 3DEC model used to analyse toppling failure

\subsection{Properties}

The rock mass properties adopted for the base case models are presented in Table 3. For the rock mass and toppling models, the rock mass is represented using a linear-elastic perfectly-plastic Mohr-Coulomb constitutive model with tensile strength cutoff. The shear strength (cohesion and friction angle) and tensile strength were estimated using the Hoek-Brown failure criterion, as described by Hoek et al. (2002). The shear strength for the materials was estimated by fitting a linear Mohr-Coulomb envelope to the non-linear Hoek-Brown curve. The maximum confining stress used for the determination of the shear strength parameters was limited to $1.0 \mathrm{MPa}$. AD factor of 1.0 was assumed for the entire rock mass. Young's modulus for the rock mass $\left(E_{r m}\right)$ was estimated based on the GSI, the intact Young's modulus $\left(E_{i}\right)$ and the $D$ factor using the equation provided by Hoek \& Diederichs (2006), while Poisson's ratio for the rock mass $\left(v_{r m}\right)$ was estimated based on the GSI using the relation derived from Hoek et al. (1995). The dilation angle is assumed to be $10^{\circ}$. For the wedge analyses, the rock mass is represented using a linear-elastic model, with the properties (density, Young's modulus and Poisson's ratio) shown in Table 3.

Table 3 Rock mass properties adopted for base case analyses

\begin{tabular}{lllllllllllll}
\hline $\begin{array}{l}\rho \\
\left(\mathbf{t} / \mathbf{m}^{3}\right)\end{array}$ & $\begin{array}{l}E_{i} \\
(\mathrm{GPa})\end{array}$ & $\begin{array}{l}\sigma_{c i} \\
(\mathrm{MPa})\end{array}$ & $\mathrm{GSI}$ & $\boldsymbol{m}_{\boldsymbol{i}}$ & $\boldsymbol{D}$ & $\begin{array}{l}\max \\
\sigma_{3} \\
(\mathrm{MPa})\end{array}$ & $\begin{array}{l}\boldsymbol{C} \\
(\mathrm{kPa})\end{array}$ & $\begin{array}{l}\boldsymbol{\phi} \\
\left({ }^{\circ}\right)\end{array}$ & $\begin{array}{l}\sigma_{t m} \\
(\mathrm{kPa})\end{array}$ & $\begin{array}{l}\boldsymbol{\Psi} \\
\left({ }^{\circ}\right)\end{array}$ & $\begin{array}{l}E_{r m} \\
(\mathrm{GPa})\end{array}$ & $\boldsymbol{V}_{r m}$ \\
\hline 2.8 & 40 & 50 & 45 & 15 & 1.0 & 1 & 257 & 36.6 & 18 & 10 & 2.03 & 0.25 \\
\hline
\end{tabular}

$\rho=$ Density; $c=$ Rock mass cohesion; $E_{i}=$ Young's modulus for the Intact Rock; $\phi=$ Rock mass friction angle; $\sigma_{t m}=$ Rock mass tensile strength; $\mathrm{GSI}=$ Geological Strength Index; $\psi=$ Rock mass dilation angle; $D=$ Hoek-Brown disturbance factor; $v_{r m}=$ Poisson's ratio for the rock mass; $\sigma_{3}=$ Minor principal stress; $E_{r m}=$ Young's modulus for the rock mass; $\sigma_{c i}=$ Uniaxial compressive strength of intact rock; $m_{i}=$ Hoek-Brown material constant for intact rock

For the wedge and toppling analyses, the structures are represented with an elastic/plastic constitutive model with Coulomb slip failure using the properties shown in Table 4. 
Table 4 Structure properties adopted for base case 3DEC wedge and toppling analyses

\begin{tabular}{llllllllll}
\hline & \multicolumn{3}{c}{ Wedge analyses } & \multicolumn{5}{c}{ Toppling analyses } \\
\hline $\boldsymbol{k}_{n}(\mathrm{GPa} / \mathrm{m})$ & $\boldsymbol{k}_{s}(\mathrm{GPa} / \mathrm{m})$ & $\boldsymbol{c}(\mathbf{k P a})$ & $\phi\left(^{\circ}\right)$ & $\boldsymbol{\sigma}_{t}(\mathbf{k P a})$ & $\boldsymbol{\Psi}\left({ }^{\circ}\right)$ & $\boldsymbol{c}(\mathbf{k P a})$ & $\phi\left(^{\circ}\right)$ & $\sigma_{t}(\mathbf{k P a})$ & $\boldsymbol{\Psi}\left({ }^{\circ}\right)$ \\
\hline 10 & 1 & 0 & 35 & 0 & 0 & 125 & 35 & 30 & 0
\end{tabular}

$k_{n}=$ Normal stiffness; $c=$ Cohesion $\sigma_{t}=$ Tensile strength; $k_{s}=$ Shear stiffness $\phi=$ Friction angle; $\psi=$ Dilation angle

\subsection{In situ stresses and groundwater}

For the base case analyses, the vertical in situ stress is lithostatic (based on the weight of the rock above). The horizontal in situ stress is equal in all directions, and its magnitude is equal to the vertical stress magnitude (i.e. the horizontal to vertical stress ratio is $1: 1$ ). The base case analyses are assumed to be dry (i.e. no pore pressures are defined in the models).

\subsection{Strength reduction analyses}

Strength reduction analyses have been performed to estimate the FoS of the slope. This involves reducing the shear and tensile strength values for both the rock mass and any explicit structures by a selected factor. The FoS is then defined as the actual strength divided by the strength required to maintain slope stability. If the actual strength is higher than the required strength, the FoS is greater than 1.0. For the modelling presented here, a convergence criterion is used to assess slope stability. That is, the model is assessed to determine whether equilibrium is reached (representing a stable slope) or continuing plastic flow is reached (representing slope failure).

\section{$4 \quad$ Base case modelling results}

\subsection{Rock mass failure}

For the model analysing rock mass failure, the slope is stable after excavation using the base case model inputs discussed above. The cumulative displacement magnitude at a point on the crest in the centre of the model is $37 \mathrm{~mm}$. Strength reduction analyses for the base case model produce a FoS of 1.55 . Isometric and vertical section views showing the failure mechanism produced by the strength reduction analyses are presented in Figure 5. It is seen that the model produces a circular-shaped rock mass failure (when the strength properties are reduced to a level where slope instability occurs).

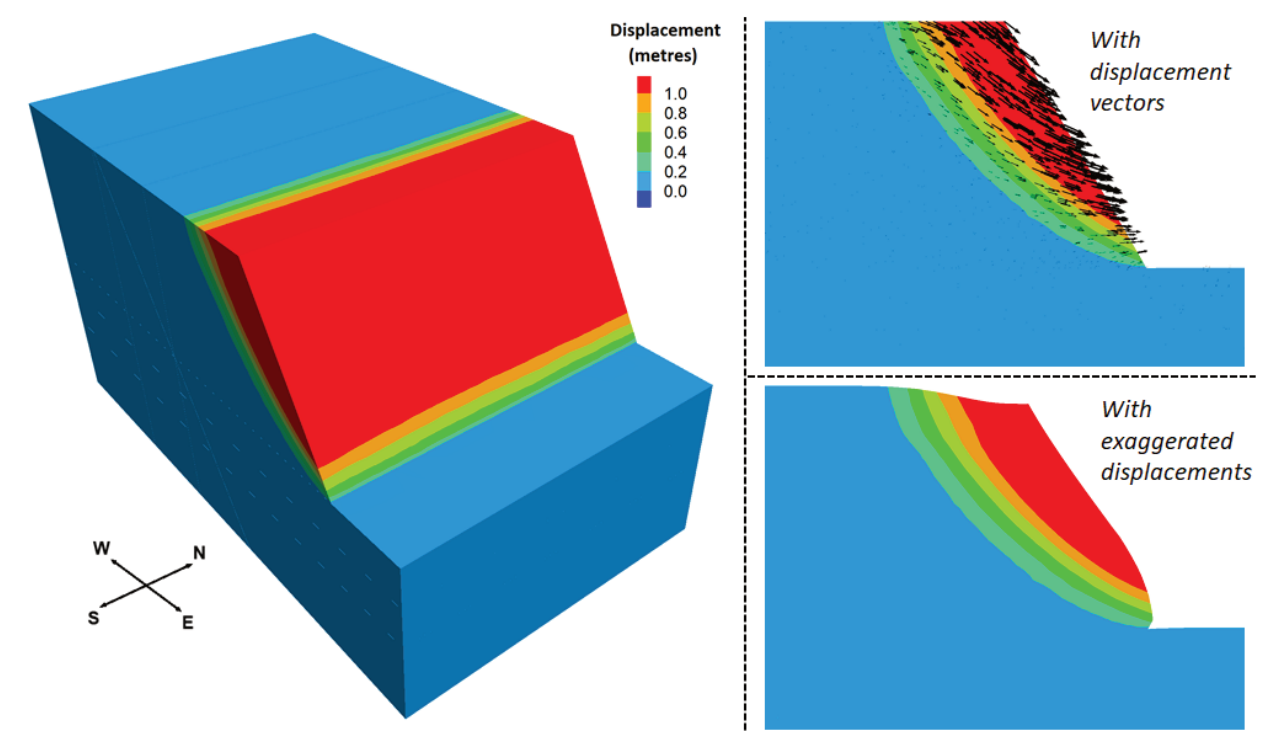

Figure 5 Cumulative displacement contours produced by base case 3DEC model used to analyse rock mass failure; showing failure mechanism after strength reduction 


\subsection{Wedge failure}

For the model analysing wedge failure, the slope is stable after excavation using the base case model inputs. The cumulative displacement magnitude at a point on the crest in the centre of the model is $3.7 \mathrm{~mm}$. Strength reduction analyses for the base case model produce an FoS of 1.34. Isometric and vertical section views showing the failure mechanism are presented in Figure 6. The model produces a wedge failure along the two structures that are explicitly defined in the model (when the strength properties are reduced to a level where slope instability occurs).

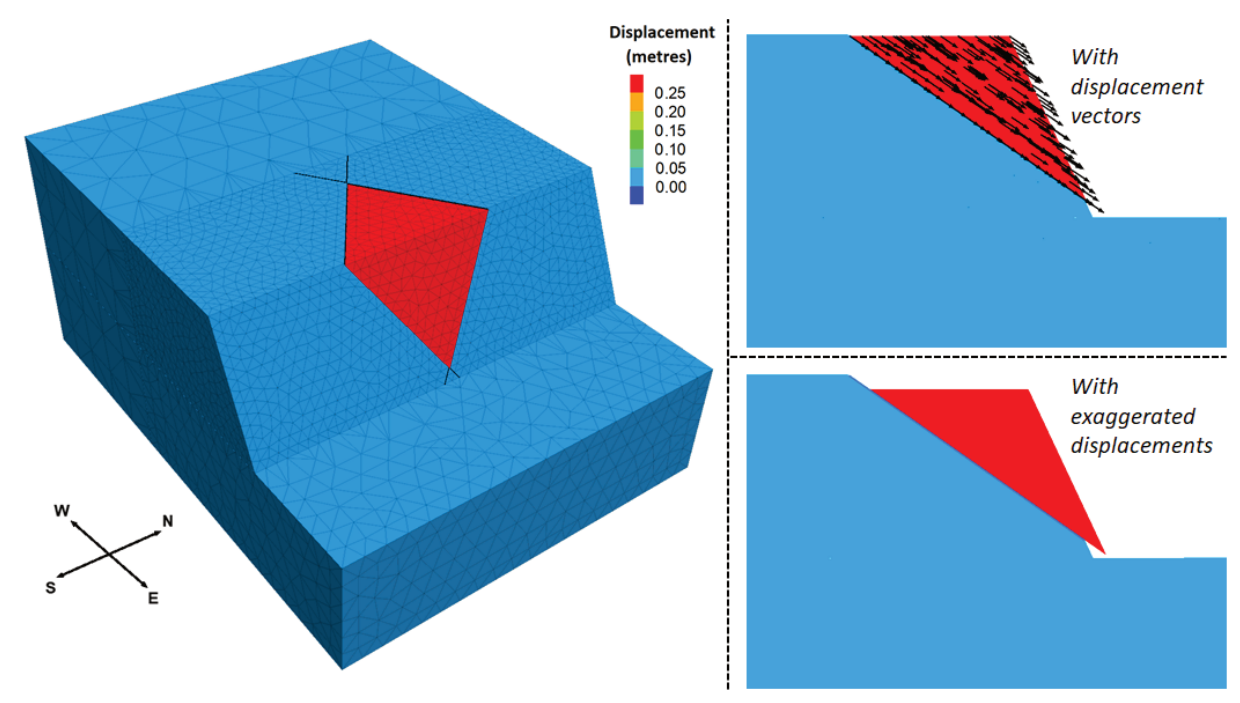

Figure 6 Cumulative displacement contours produced by base case 3DEC model used to analyse wedge failure; showing failure mechanism after strength reduction

\subsection{Toppling failure}

For toppling failure, the slope is stable after excavation using the base case model inputs. The cumulative displacement magnitude at a point on the crest in the centre of the model is $10 \mathrm{~mm}$. Strength reduction analyses for the base case model produce an FoS of 1.37. Isometric and vertical section views showing the failure mechanism are presented in Figure 7. The model produces a toppling failure along the structures that are explicitly defined (when the strength properties are reduced to a level where slope instability occurs). Note that the FoS is 1.58 when the joints are effectively 'glued' together with very high strength properties.

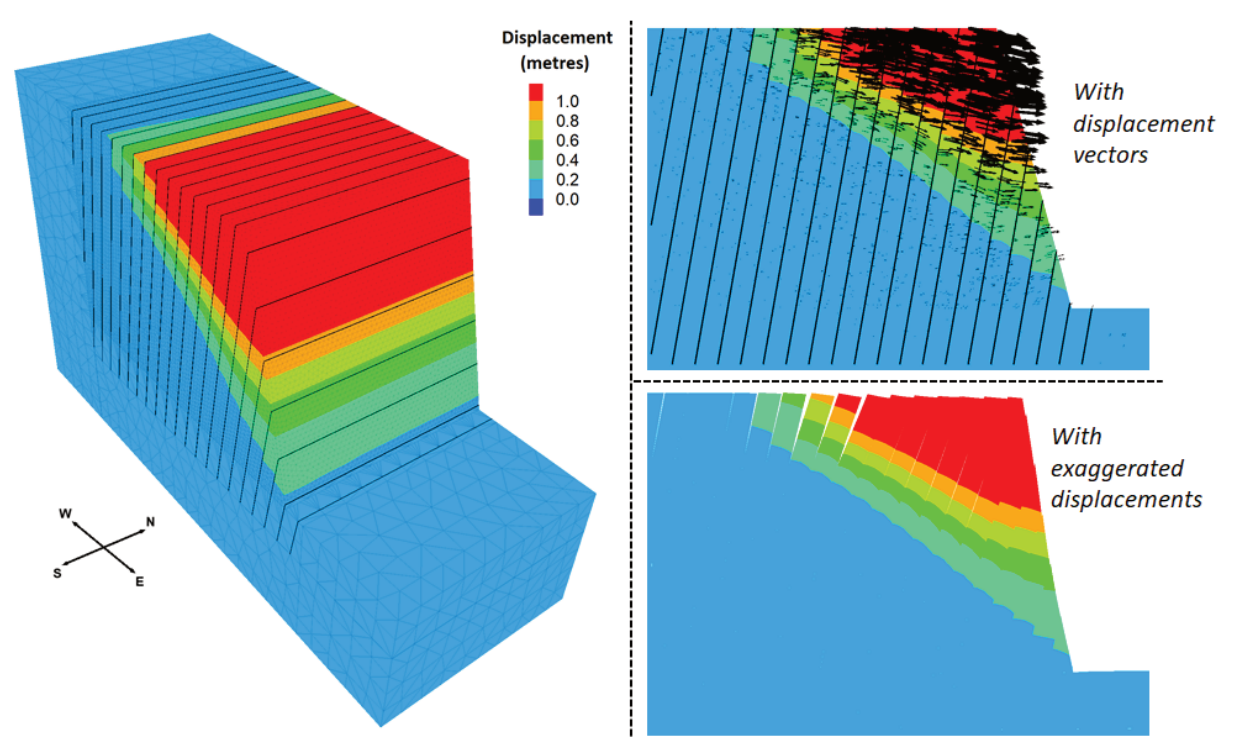

Figure 7 Cumulative displacement contours produced by base case 3DEC model used to analyse toppling failure; showing failure mechanism after strength reduction 


\section{$5 \quad$ Effect of selected inputs on model behaviour}

\subsection{Rock density}

Density has a significant effect on both the FoS and displacements for the rock mass and toppling mechanisms (Tables 1 and 2). Increasing the density increases the driving forces, resulting in a reduced FoS and increased displacement magnitudes. Interestingly, for the wedge failure, density has a significant effect on displacements but a negligible effect on FoS. Changing the density does not affect the FoS in this case because an increased density will increase both the normal stress and the shear stress acting along the structures. The increase in shear stress will increase the likelihood of failure, however, the increase in normal stress will reduce the likelihood of failure due to an increase in shear strength.

\subsection{Rock mass properties}

Sensitivity analyses have been performed for the rock mass and toppling failure models by varying the Young's modulus, Poisson's ratio, cohesion, friction angle, tensile strength, dilation angle, UCS, GSI and $m_{i}$. Results are summarised in Tables 1 and 2, and the following observations are provided:

- Of the rock mass parameters that were varied, the shear strength (rock mass cohesion and friction angle) has the greatest influence on the resulting FoS.

- For the rock mass failure model, the adopted rock mass shear strength (cohesion and friction angle) has a significant effect on FoS. This is not surprising given that the failure mechanism involves mainly shear failure through the rock mass. However, the adopted shear strength values do not have a significant effect on the resulting displacements (unless slope failure is predicted).

- For the rock mass failure model, the adopted tensile strength has a negligible effect on both FoS and displacements. This is because the failure mechanism involves mainly shear (not tensile) failure through the rock mass. For the toppling model, the rock mass tensile strength does have a minor effect on FoS, because the failure mechanism includes tensile failure in the rock mass.

- The Young's modulus has a significant effect on displacements but not FoS. Interestingly, halving the rock mass modulus results in a doubling of the modelled displacement at the crest (for the rock mass failure model). The effect of the modulus is studied and discussed in more detail below. Note that the effect of the modulus on FoS can be more significant if a strain-softening model is used.

- The Poisson's ratio has an effect on displacements but not FoS. Interestingly, the displacements increase when the Poisson's ratio is decreased. Decreasing the Poisson's ratio decreases the bulk modulus (ratio of volumetric stress to volumetric strain) and increases the shear modulus (ratio of shear stress to shear strain). Sensitivity analyses have also been run to assess these two parameters and the results are presented in Figure 8. It is seen that both parameters have a small effect on FoS and a significant effect on displacement. Reducing the Poisson's ratio has more effect on the bulk modulus than the shear modulus (i.e. it reduces the bulk modulus more than it increases the shear modulus), which is why reducing the Poisson's ratio results in an increased displacement magnitude. Note that the Poisson's ratio may have more effect on FoS if a strain-softening model is used.

- The rock mass dilation angle has a negligible effect on FoS and displacements.

- Based on the sensitivity analyses with varied UCS, GSI and $m_{i}$ values (for the rock mass failure model only), the GSI has the greatest effect of the three parameters on the resulting FoS and model displacements. Note that the GSI affects both the rock mass strength and the rock mass modulus. 


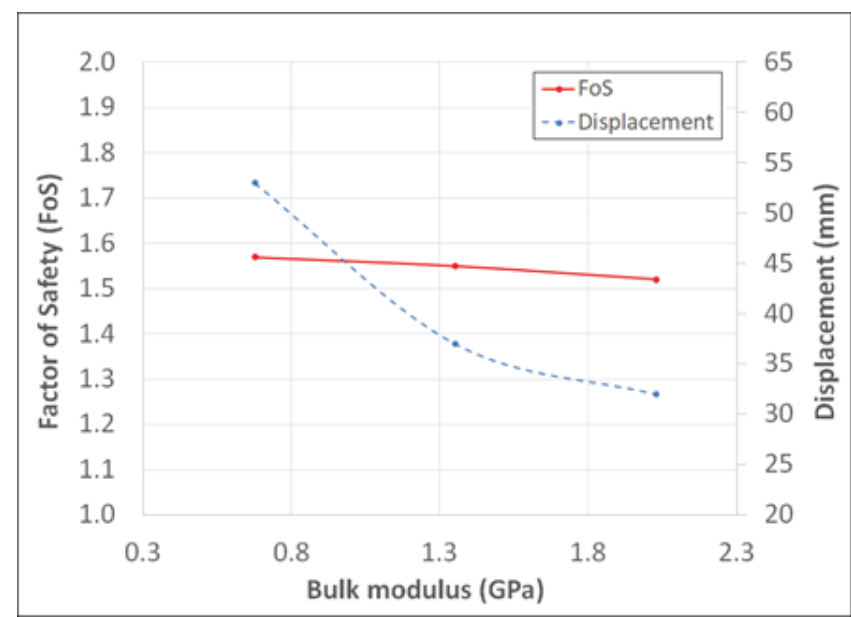

(a)

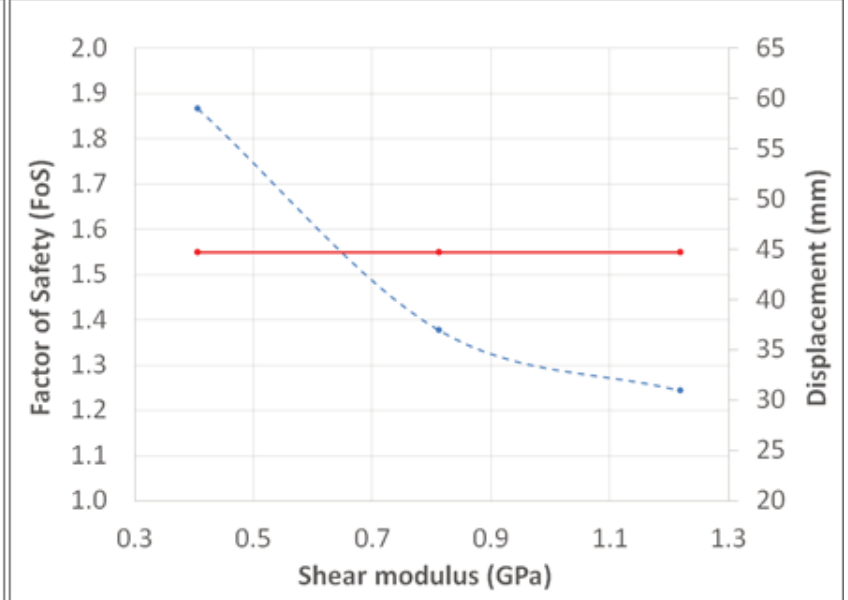

(b)

Figure 8 Sensitivity analysis for rock mass failure 3DEC model, with (a) Different bulk modulus; and (b) Different shear modulus

The effect of other inputs relating to the rock mass properties have also been assessed using the rock mass failure model. The base case analyses include a $D$ factor of 1.0, while the model was also run with $D$ factors of $0,0.5$ and 0.7 . In each case, one $D$ factor is assigned to the entire rock mass. The resulting FoS and model displacements are presented in Figure 9(a). It is seen that the adopted $D$ factor has a significant effect on both FoS and displacements. Note that, for these analyses, an increased $D$ factor decreased both the rock mass strength and the rock mass modulus.

When estimating linear Mohr-Coulomb shear strength properties (cohesion and friction angle) based on a non-linear Hoek-Brown curve, an upper confining stress needs to be selected. Sensitivity analyses have also been performed whereby the adopted strength parameters are estimated using different upper confining stresses, and the resulting FoS and model displacements are presented in Figure 9(b). It is seen that the adopted upper confining stress has a small effect on FoS and a negligible effect on displacements.

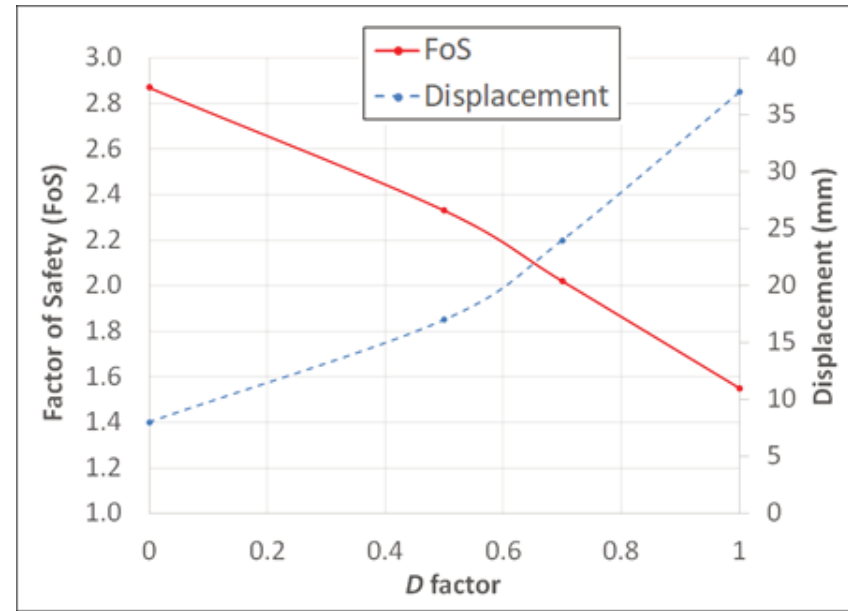

(a)

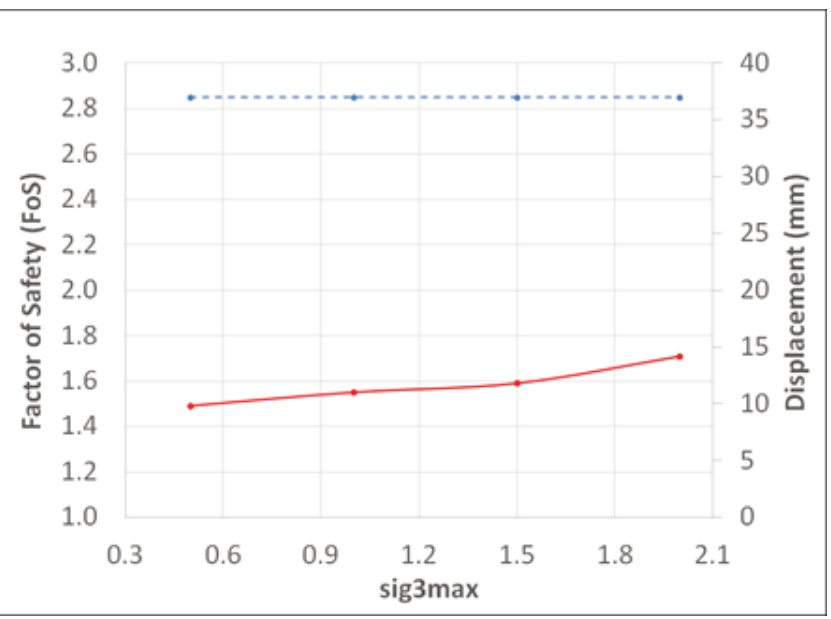

(b)

Figure 9 Sensitivity analysis for rock mass failure 3DEC model; with (a) Different $D$ factors; and (b) Different upper confining stresses used to estimate the rock mass strength

For the analyses presented above, changing the rock mass modulus has a significant effect on displacements but a negligible effect on FoS. Note that, for these base case analyses, the rock mass is represented using a perfectly-plastic Mohr-Coulomb model, whereby the rock mass strength is maintained regardless of how much failure (or strain) occurs. The modulus may have more effect on FoS if a strain-softening model was 
used (i.e. where the rock mass strength can reduce based on the plastic shear strain). To test this, an additional model was run with the rock mass represented using a strain-softening model. The results of these strain-softening analyses, along with the results of the base case analyses, are presented in Figure 10. For the model with strain-softening, reducing the modulus results in a small reduction in FoS. The effect of the modulus is therefore dependent on whether the rock mass is represented using a perfectly-plastic or strain-softening model. The effect of the modulus may be more significant in a strain-softening model if the stability was marginal (i.e. if the FoS was lower). Also, as for the modulus, the effect of Poisson's ratio on FoS may be greater if a strain-softening model was used. Note that, for the strain-softening analyses presented here, strain-softening is implemented during excavation but not during the strength reduction process. That is, the strength properties are 'frozen' after excavation and the strength reduction analyses are run based on those 'frozen' properties (and assuming perfectly-plastic behaviour).

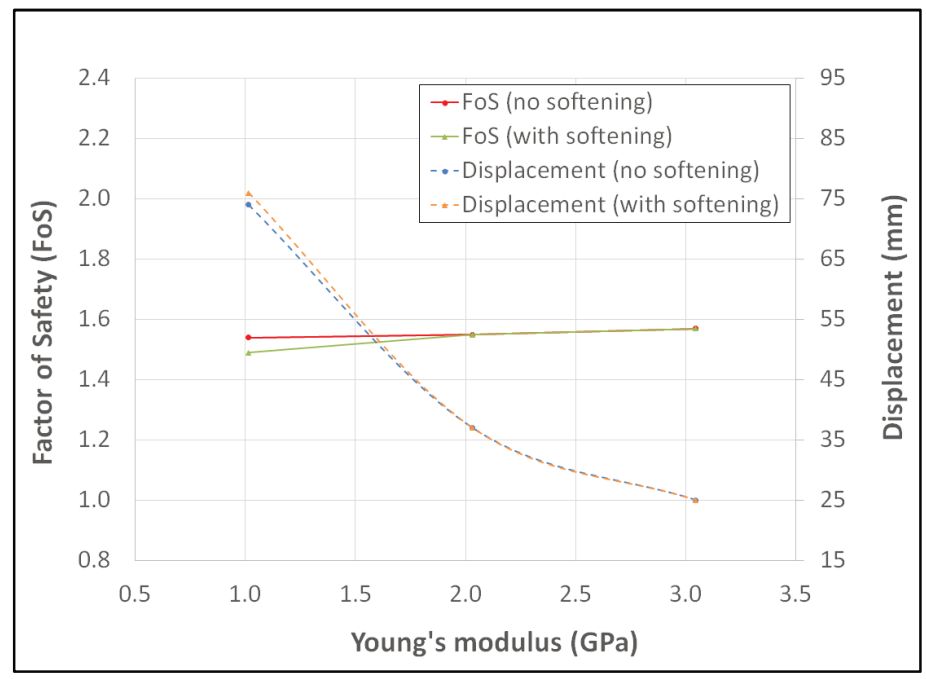

Figure 10 Sensitivity analysis for rock mass failure 3DEC model; with different rock mass modulus, for models with and without strain-softening in the rock mass

\subsection{Structure properties}

Sensitivity analyses have been performed for the wedge and toppling failure models by varying several structure properties (normal stiffness, shear stiffness, cohesion, friction angle, tensile strength and dilation angle). The results are summarised in Tables 1 and 2, and the following observations are provided:

- The normal and shear stiffness for the structures have a negligible effect on both FoS and displacements (based on the ranges adopted for the analyses).

- The cohesion and friction angle for the structures have a significant effect on FoS and a negligible effect on displacements (unless slope failure occurs).

- The tensile strength for the structures has a negligible effect on FoS and displacements for the wedge analysis. This is because shear (not tensile) failure occurs along the structures. The tensile strength for the structures has a minor effect on FoS for the toppling model.

- The dilation angle has a negligible effect on FoS and displacements for the wedge and toppling analyses. Note that, in 3DEC, the effect of dilation is indirect. For a simple sliding failure (such as a wedge), the dilation does not affect the shear strength. If the model is constrained, the dilation causes an increase in normal stress that affects the yielding shear stress.

\subsection{Pore pressures}

Sensitivity analyses have been run with different phreatic surfaces at selected distances behind the face, with hydrostatic conditions assumed below each surface. The results are presented in Figure 11. In all cases, pore 
pressure has a significant effect on FoS. For the rock mass and wedge analyses, pore pressures have a negligible effect on displacements (except where the FoS is less than 1). For the toppling model, the pore pressures have a significant effect on both FoS and displacements.

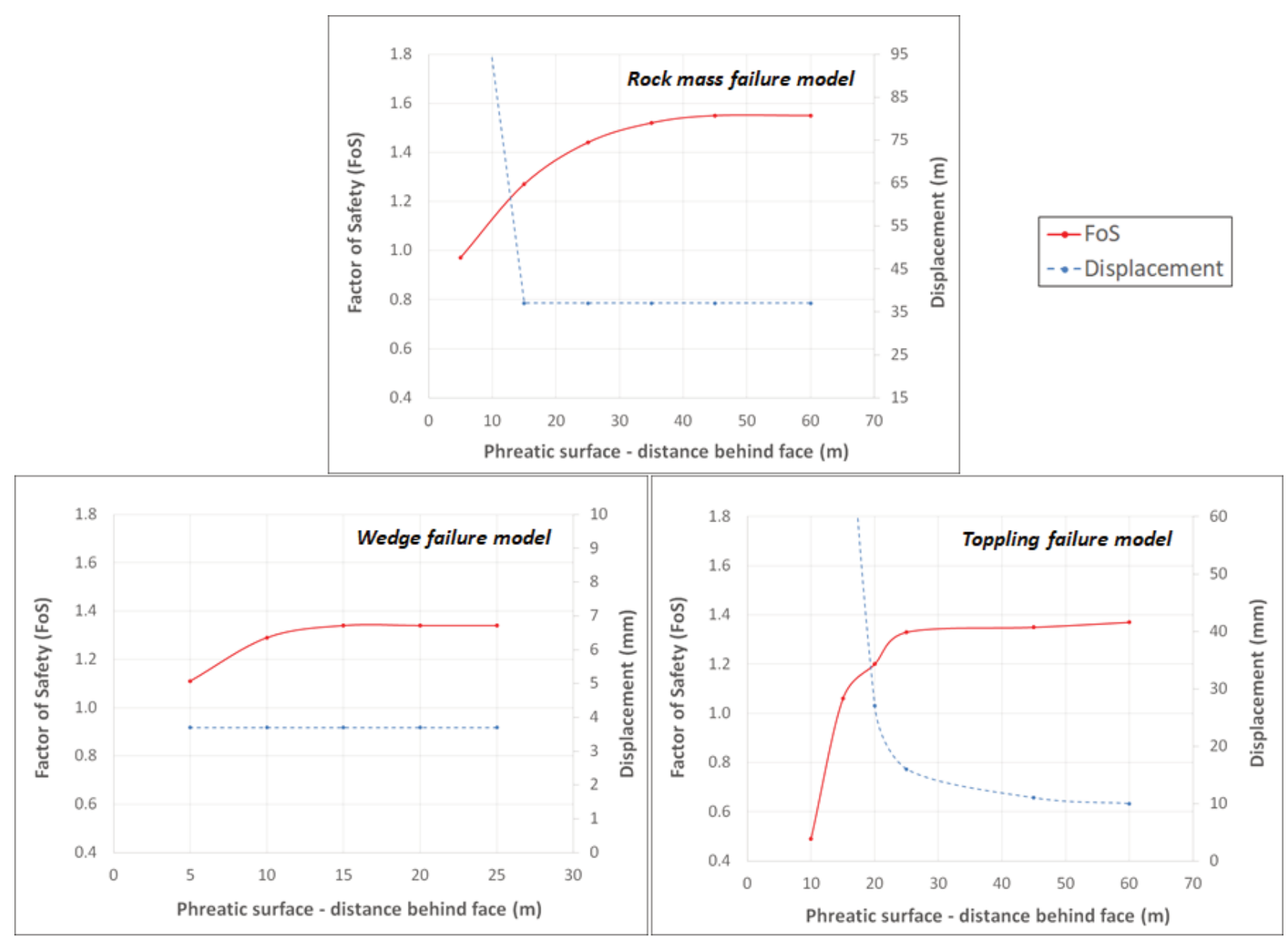

Figure 11 Sensitivity analysis results with different phreatic surface locations

\section{$5.5 \quad$ In situ stresses}

Sensitivity analyses have been performed with different pre-mining in situ stresses. For the base case, a horizontal to vertical stress ratio of 1:1 was assumed. Additional models were run with ratios of 0.5:1, 1.5:1, 2:1 and 3:1. The resulting FoS and model displacements are presented in Figure 12(a) (for the rock mass failure model). It is seen that the adopted stresses have a significant influence on displacements and a small influence on FoS. For these results, the horizontal stresses are assumed to be equal in all directions. Additional analyses have been run with the north-south stresses different to the east-west stresses, and the results are summarised in Figure 12(b) (along with the base case results, for the rock mass failure model). Note that the slope strikes north-south. It is seen that the high east-west stresses (ratio 3:1:1) produce the highest displacements, because the east-west direction is oriented perpendicular to (or out of) the slope. Also note that the FoS reduces when the stresses are increased parallel to the slope (ratio 1:3:1).

Note that these results are applicable for the slope height being analysed and the adopted constitutive model. If a higher slope and a different constitutive model was used (e.g. Hoek-Brown), the model response to the in situ stress assumptions may be different. 


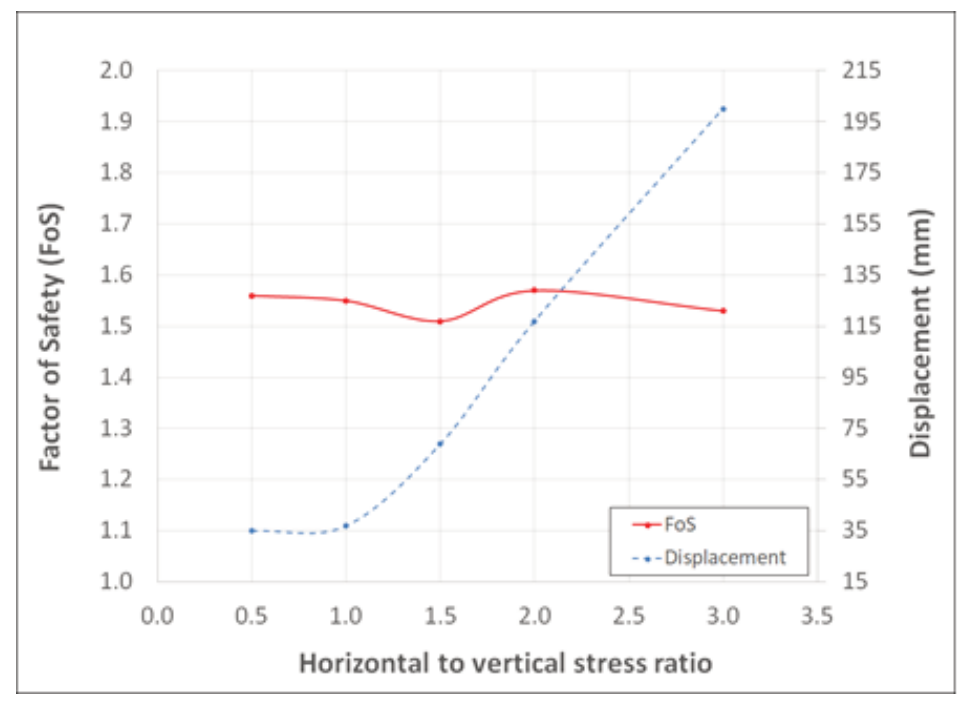

(a)

\begin{tabular}{|c|c|c|}
\hline $\begin{array}{c}\text { Stress Ratio } \\
\text { (East-West:North-South:Vertical) }\end{array}$ & FoS & $\begin{array}{c}\text { Displace ment at crest } \\
\text { (mm) }\end{array}$ \\
\hline $1: 1: 1$ & 1.55 & 37 \\
\hline $3: 1: 1$ & 1.54 & 210 \\
\hline $1: 3: 1$ & 1.50 & 39 \\
\hline
\end{tabular}

(b)

Figure 12 Sensitivity analysis for rock mass failure 3DEC model, with (a) Different pre-mining in situ stresses; and (b) Different horizontal stress assumptions

Similar sensitivity analyses have been performed for the wedge and toppling models, and the results are presented in Figures 13 and 14. For the wedge analyses (Figure 13), the adopted stresses have a significant influence on displacements, with displacements increasing as the horizontal stresses are increased. There is also a small increase in FoS as the horizontal stress is increased. This may be due to increased confinement created by the increased horizontal stresses. Note that the slope strikes north-south. Assuming non-uniform horizontal stresses has a significant influence on the model behaviour. If the horizontal stresses are increased along the strike of the slope only (1:3:1 ratio), the FoS increases. If the horizontal stress is increased perpendicular to (or out of) the slope only (3:1:1 ratio), the FoS reduces and displacements increase significantly. This suggests that the increase in FoS seen in Figure 13(a) is caused by the increasing stresses parallel to the slope.

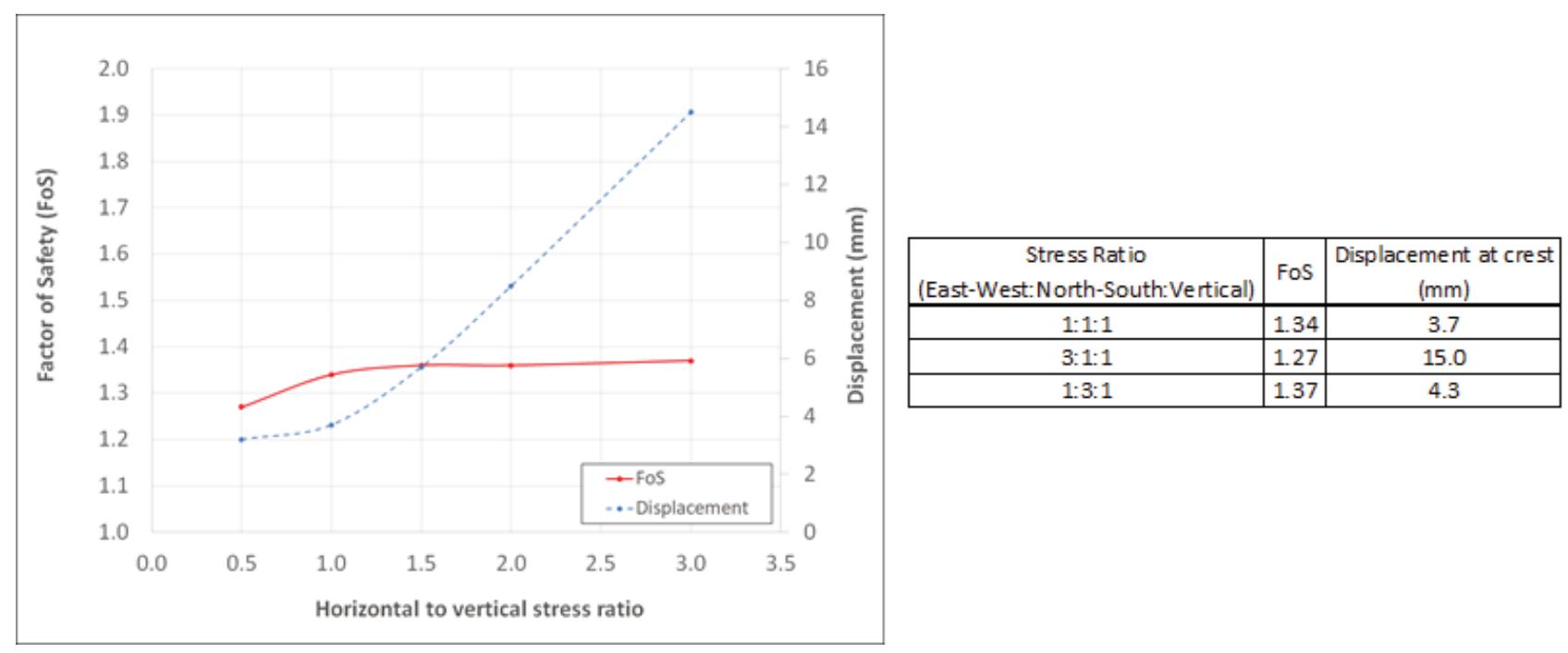

(a)

(b)

Figure 13 Sensitivity analysis for wedge failure 3DEC model, with (a) Different pre-mining in situ stresses; and (b) Different horizontal stress assumptions

For the toppling analyses (Figure 14), the adopted stresses have a significant influence on displacements, with displacements increasing as the horizontal stresses are increased. The stresses have a small effect on 
FoS. Note that the slope strikes north-south. It is seen that assuming non-uniform horizontal stresses has a significant influence on the model behaviour. If the horizontal stresses are increased along the strike of the slope only (1:3:1 ratio), the FoS decreases. If the horizontal stress is increased perpendicular to (or out of) the slope only (3:1:1 ratio), the FoS does not change, but displacements increase significantly. This is consistent with the behaviour of the rock mass failure model.

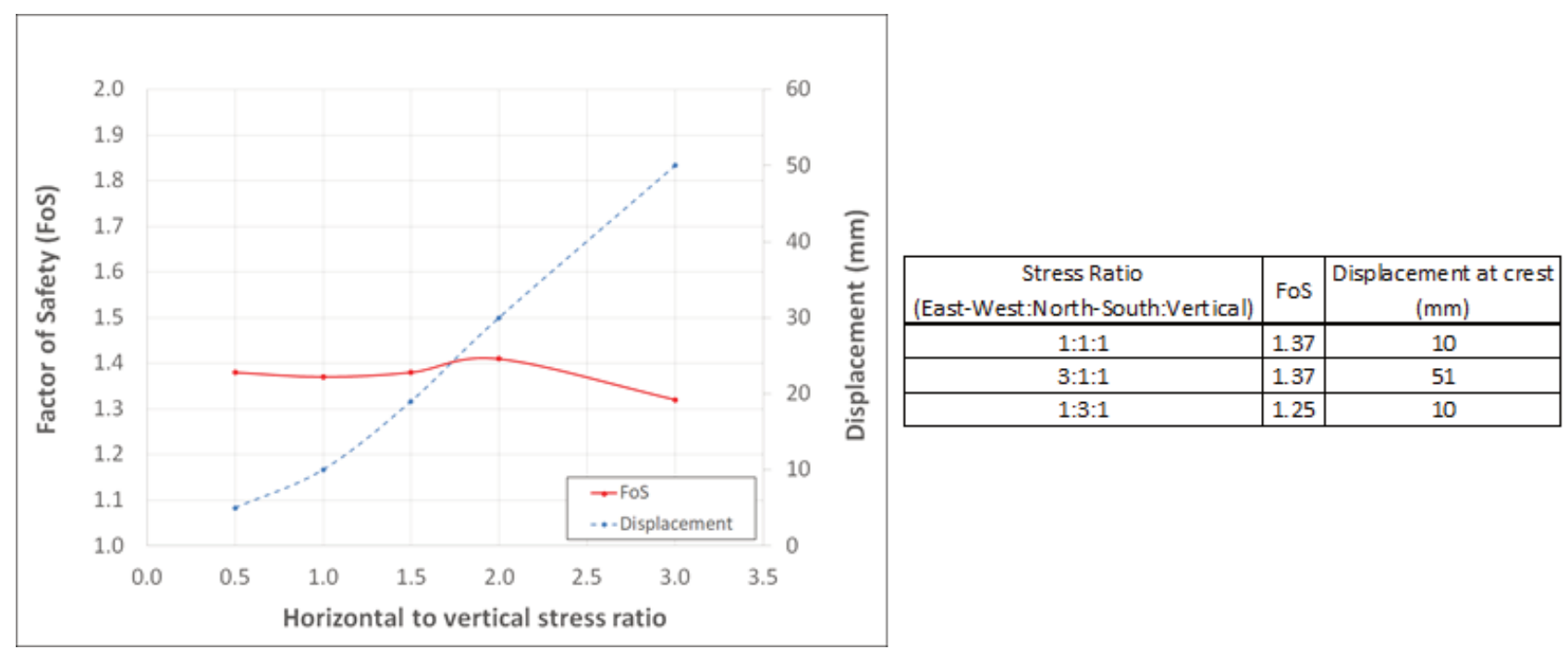

(a)

(b)

Figure 14 Sensitivity analysis for toppling failure 3DEC model, with (a) Different pre-mining in situ stresses; and (b) Different horizontal stress assumptions

\subsection{Model zone (or element) size}

Other numerical modelling considerations can also influence the results. For example, the zone (or element) size used in a model can affect the key model outputs. There needs to be a sufficient number of zones (or an adequate zone resolution) in the area of interest (e.g. over the height of a slope) for the model to produce reliable results. Sensitivity analyses have been performed using the rock mass failure and toppling models with different zone sizes, and the results are shown in Figure 15. It is seen that an increased zone size results in a significant increase in FoS.

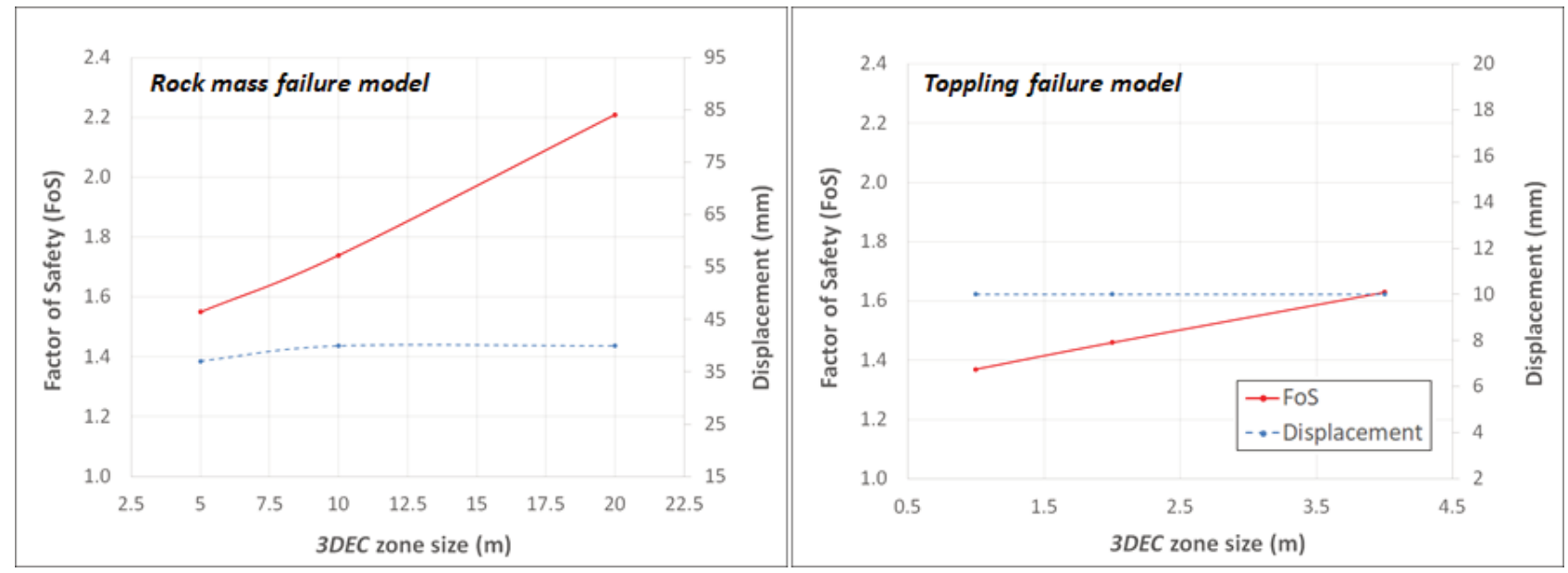

Figure 15 Sensitivity analyses with different model zone (or element) sizes

Note that for these models, the FoS is still reducing down to the adopted zone size. This suggests that, if the models were to be relied upon for slope stability estimates, the zone size may need to be reduced. Lorig et al. (2009) state that at least 30 lower-order elements are required over the slope height of interest. For the rock 
mass model, there are 20 zones over the slope height, while for the toppling model, there are 50 zones over the slope height. 3DEC's tetrahedral zones have been used for all analyses presented in this paper.

\section{Discussion and conclusions}

\subsection{Rock density}

For the rock mass and toppling analyses, the adopted density has a significant effect on FoS. It is therefore worthwhile undertaking sufficient sampling and testing to obtain a good understanding of the density. A large amount of density test data is often available from other non-geotechnical sources, which can be used to supplement the geotechnical data.

\subsection{Rock mass and structure strength}

For the three analysed failure mechanisms, the shear strength of the rock mass and/or explicit structures has a significant influence on FoS. Therefore, geotechnical field and laboratory investigations should include a significant component aimed at improving understanding of the shear strength of the soil, rock mass and structures. The assumed rock mass tensile strength can also have some effect, particularly for a toppling failure where tensile failure may be important.

Which strength parameters are most important depends on the failure mechanism. For example, rock mass shear strength is most important for circular failures, which involve shear failure through the rock mass. The structure shear strength is most important for wedge failures, which involve shear failure along discontinuities. Tensile strength of the rock mass and structures is not important for the circular and wedge failures, which involve little or no tensile failure. Tensile strength is more important for toppling failures, which involve tensile failure along the steeply-dipping discontinuities.

The adopted $D$ factor has a significant influence on FoS, because it has a significant effect on the adopted rock mass shear strength parameters. In the author's experience, a $D$ factor of between 0.7 and 1.0 is often adopted for the rock mass behind the excavation face for open pit analyses. Changes to the assumed $D$ factor (value and depth behind the face) could potentially override any refinements to the strength parameters that are obtained from additional geotechnical investigations. For the rock mass failure analyses presented above, changing the $D$ factor from 0.7 to 1.0 results in a $23 \%$ reduction in FoS. This shows that a relatively small change in the $D$ factor could control the acceptability of a pit design. Others have presented similar results. Baczynski et al. (2011) performed 2D numerical analyses to assess slope stability at the OK Tedi open pit, and found that increasing the width of disturbed ground behind the slope face resulted in a 15\% reduction in FoS.

This is a significant issue given that no clear guidelines exist for the selection of a $D$ factor. In the 2009 publication Guidelines for Open Pit Slope Design, the most relevant reference to the $D$ factor is provided by Karzulovic \& Read (2009), who state that the influence of the $D$ factor is large and its application requires 'experience and judgement'. Silva \& Gómez (2015) state that: “The spatial distribution of the $D$ factor, as well as its value, remain unresolved issues in the current rock mechanics practice applied to slope stability analysis". The importance of the selected $D$ factor could override any refinements made to the model inputs based on additional field investigation, laboratory testing programs, etc. For example, for the analyses presented above, the effect of reducing the $D$ factor from 1.0 to 0.7 on the resulting shear strength is similar to increasing the UCS from 50 to $115 \mathrm{MPa}$.

Careful consideration should be given to selecting an appropriate $D$ factor, and the selected value/s (and therefore rock mass strength) should be verified via back-analysis of existing slopes where possible. Silva \& Gómez (2015) propose an empirically-based guideline for the distribution of disturbance with depth in a slope. Rose et al. (2018) also propose an empirical rock mass disturbance rating system to assist with initial scoping of the potential fully-disturbed limit or depth behind the slope face.

The appropriate rock mass strength properties to assign to a numerical model will depend on the constitutive model used to represent the rock mass (e.g. perfectly-plastic, strain-softening, etc.). Cancino et al. (2018) 
discuss the use of strain-softening models for slope stability analyses. The appropriate properties will also depend on whether rock mass variability is defined in the model. Lorig (2009) performed modelling using FLAC (Itasca Consulting Group 2005) to assess the effects of rock mass variability on slope stability. He found that assigning some rock mass strength variability to the model generally resulted in a less stable outcome when compared to assigning one set of parameters based on the average dataset.

When estimating linear Mohr-Coulomb shear strength properties (cohesion and friction angle) based on a non-linear Hoek-Brown curve, an upper confining stress needs to be selected. Careful consideration should be given to the adopted upper confining stress for each particular analysis based on the actual stress conditioned expected in the area of interest. For example, the upper confining stress used for a relatively shallow open pit analysis should be significantly lower than that used for a deep underground analysis. Adopting a bilinear (instead of linear) model will also provide an improved fit to the Hoek-Brown curve. Using a Hoek-Brown model (instead of a Mohr-Coulomb model) will eliminate this issue.

In a hard rock open pit environment, failures are often structurally-controlled with little or no rock mass failure. However, given that the location/orientation of all small to medium-scale structures is generally not known, and in most cases all structures will not be explicitly-defined in a numerical model, the assumed strength of the 'rock mass' is often a controlling factor in the results of the numerical slope stability analyses. For example, if a large fault daylights in the slope and strikes oblique to the pit face, breakout through the rock mass will be required for failure to occur in the model. Therefore, although circular rock mass failures are highly unlikely in a hard rock environment, knowledge of the rock mass strength may still be crucial in producing reliable stability estimates (particularly where large parts of a model include a continuum representation of the rock mass).

The appropriate fault properties to assign to a model may depend on how the structure is represented in the model. For example, if the structure is represented explicitly, it will probably behave differently to how it would behave if it was represented by assigning a lower strength to selected model zones (or by defining 'ubiquitous joints' to the model zones along the fault). Severin (2018) discusses different ways to represent faults in numerical models and shows that this can significantly affect the results.

\subsection{Elastic rock mass properties}

The assumed rock mass modulus can have a significant effect on model displacements. This is consistent with the work of others. Based on 2D numerical analyses at OK Tedi, Mylvaganum et al. (2011) state that the horizontal rebound is sensitive to the rock mass modulus values. If the rock mass is assumed to be perfectly-plastic, the modulus will have a negligible effect on FoS. If the rock mass is represented using a strain-softening model, the modulus may have an effect on FoS.

The assumed rock mass modulus may affect displacements but not FoS, while the adopted rock mass strength may affect FoS but not displacements. This highlights that achieving a reasonable 'calibration' between the model and monitored displacement magnitudes does not necessarily indicate that a model is reliable. A good 'calibration' may be achieved because the assumed modulus is accurate, however, the adopted strength may be incorrect. The best way to improve confidence in the adopted strength properties is to back analyse slope failures. It is also noted that the model inputs that provide a successful calibration or back-analysis may not be determinant or unique (i.e. different combinations of inputs may produce the same model behaviour).

\subsection{Groundwater}

Pore pressures within the rock mass and/or structures reduce the effective normal stress and therefore reduce the shear strength. The assumed groundwater conditions have a significant effect on the model behaviour for the three analysed failure mechanisms. This is consistent with the work of others. For example, El-Idrysy (2013) and Khanmohammadi \& Hosseinitoudeshki (2014) performed numerical analyses to assess slope stability and found that the assumed water levels/pore pressures have a significant influence on FoS (higher pressures result in a lower FoS). This is also consistent with experience, with several known slope 
failures having been influenced by pore pressures (e.g. when dewatering/depressurisation is discontinued, leaking pipes, after significant rainfall events, etc.).

Improved knowledge of the pore pressures behind the slope can provide a significant improvement in the reliability of slope stability analyses. Installing in-pit piezometers to provide an indication of the pore pressures in the immediate vicinity of potential failures is beneficial (often piezometers only exist behind the pit crest). Performing detailed hydrogeological modelling can also provide improved pore pressure estimates when compared to adopting a simple phreatic surface with hydrostatic conditions below. Assuming hydrostatic conditions below a phreatic surface may produce unrealistic pore pressure estimates, as discussed by Lorig et al. (2009). As stated by Beale (2018), pore pressure is the only parameter in a pit slope that can be readily changed. Depressurisation measures can be implemented to improve slope stability when analyses indicate that this is required.

The effect of short-term recharge due to rainfall events may also be important. Analyses will often be based on a 'base case' phreatic surface or pore pressure distribution, whereas the pore pressures may be significantly higher than this soon after rainfall. Slope failures often occur soon after significant rainfall events.

\subsection{In situ stresses}

The analyses show that in situ stresses can have an effect on FoS and displacements. This is consistent with 3D open pit slope stability analyses performed by the author, where changes in the horizontal stress ratio has produced significant changes in FoS (particularly for wedge failure mechanisms). These finding are also consistent with other work. Sjöberg (2013) used 2D numerical analyses to assess the effects in in situ stress assumptions on the modelled slope behaviour. He concludes that, in this particular case, the stresses did not appear to affect the overall stability of the slope, but they proved to be very influential on the ground deformations resulting from pit excavation. Noorani et al. (2011) used 2D numerical analyses to assess the effects of horizontal stresses on slope stability for an open pit mine in Iran. The results show that the tensile and shear failure would expand and the stability of the slope would decrease due to an increase in the horizontal stress ratio. Lorig et al. (2009) provide observations on the effects of in situ stress on slope stability, including the statement that, the larger the initial horizontal stresses, the larger the horizontal displacements. Smith (2013) discusses the effects of local stress trajectories on structures in rock slopes, and states that the critical structures will be those with orientations favourable to slip with respect the local major principal stress orientation. In terms of anecdotal evidence, Dight (2006) presents case studies of open pit slope failures where evidence suggests that stress conditions contributed to instability. For open pits (particularly if there is no associated underground mine) there is often no stress measurement data. It would be beneficial to obtain more site-specific data for the in situ stress magnitudes and orientations at depths relevant to the open pit slopes.

\subsection{Other model inputs}

Other numerical modelling inputs and simplifications (such as the model zone or element size, the model boundary location and conditions, etc.) may also have a significant effect on the reliability of the modelling results. The analyses presented above show that the model zone (or element) size can have a significant effect on FoS. This is consistent with other work. For example, based on 2D numerical analyses at OK Tedi, de Bruyn et al. (2013) note that the inclusion of the coarse zoning increased the FoS by 0.1 , while Lorig et al. (2009) also show that the FoS can increase with an increased model zone size. This is very important because even if significant effort is dedicated to understanding geotechnical conditions such as material strength, pore pressures, in situ stresses, etc., inappropriate modelling techniques (such as a zone size that is too large and/or model boundaries being too close to the excavation) can compromise the reliability of the modelling results. Both of these modelling factors (i.e. increasing the zone (or element) size and pushing the boundaries closer to the excavation) will reduce the overall size of a numerical model and reduce the model run times, which can be tempting when modelling results (and therefore answers regarding pit designs, etc.) are required within short timelines. The simplification required to perform $2 \mathrm{D}$ analyses can also reduce the 
reliability of the results. Wines (2016) provides case studies to show a significant difference in FoS produced by $2 \mathrm{D}$ and $3 \mathrm{D}$ analyses for the same slopes.

\subsection{Structural model}

When assessing the priority for geotechnical investigations for a hard rock open pit, the importance of a detailed and reliable structural model cannot be overstated. In the author's experience, when hard rock slope failures occur that have not been predicted by detailed analyses, it is often because one or more of the controlling structures did not exist in the structural database, and was therefore not defined in the model. In many cases, knowledge of the location of the controlling structures is more important than anything else. If key controlling structures are not included in a model, the model will not identify the mechanism regardless of how much effort is dedicated to understanding other issues such as rock mass strength, pore pressures, stresses, etc.

\subsection{Sensitivity studies and probabilistic analyses}

To determine the FoS for numerical slope stability analyses, strength reduction analyses will generally be performed. This is essentially a sensitivity analysis to assess what effect a change in the assumed strength properties will have on the predicted stability. Uncertainty in other important model inputs (such as the pore pressures and in situ stresses) are not accounted for within each strength reduction analysis (i.e. each strength reduction analysis will involve one pore pressure assumption and one in situ stress assumption). It is therefore beneficial to run separate sensitivity analyses with different pore pressure and in situ stress assumptions.

Numerical analyses can also be used to estimate the Probability of Failure of a slope. This can be undertaken using different techniques, such as the point estimate method and the response surface method, as described by Wesseloo \& Read (2009) and Venter (2015). Both methods involve running separate models with different parameters. The information provided above may be useful in selecting which parameters to vary. For example, in some cases, it may be worth varying the density and in many cases, it may not be worth varying the modulus.

\section{Acknowledgement}

The author thanks Dr Glenn Sharrock for undertaking a comprehensive review of this paper and providing valuable feedback.

\section{References}

Baczynski, NRP, de Bruyn, IA, Mylvaganam, J \& Walker, DJH 2011, 'High Rock Slope Cutback Geotechnics: A Case Study at Ok Tedi Mine', in E Eberhardt \& D Stead (eds), Proceedings of the 2011 International Symposium on Rock Slope Stability in Open Pit Mining and Civil Engineering, Canadian Institute of Mining, Metallurgy and Petroleum, Montreal.

Beale, G 2018, 'How Our Understanding of Water and Slope Stability has Improved Since 2009', Proceedings of the 2018 International Symposium on Slope Stability in Open Pit Mining and Civil Engineering, Asociacion Nacional de Ingenieros de Minas and Colegio Oficial de Ingenieros de Minas del Sur, Seville.

Cancino, C, Álvarez, C, Orrego, C, Díaz, M \& Ledezma, R 2018, 'Applicability of Strain Softening Models to Slope Stability Analyses', Proceedings of the 2018 International Symposium on Slope Stability in Open Pit Mining and Civil Engineering, Asociacion Nacional de Ingenieros de Minas and Colegio Oficial de Ingenieros de Minas del Sur, Seville.

de Bruyn, IA, Coulthard, MA, Baczynski, NRP \& Mylvaganam, J 2013, 'Two-dimensional and three-dimensional distinct element numerical stability analyses for assessment of the west wall cutback design at Ok Tedi Mine, Papua New Guinea', in PM Dight (ed.), Proceedings of the 2013 International Symposium on Slope Stability in Open Pit Mining and Civil Engineering, Australian Centre for Geomechanics, Perth, pp. 653-668.

Dight, PM 2006, 'Pit wall failures on 'unknown' structures', The Journal of The South African Institute of Mining and Metallurgy, vol. 106, pp. 451-458.

El-Idrysy, H 2013, 'Approach to groundwater and pore water pressure modelling for different geotechnical conditions in open pit slope stability analysis', in PM Dight (ed.), Proceedings of the 2013 International Symposium on Slope Stability in Open Pit Mining and Civil Engineering, Australian Centre for Geomechanics, Perth, pp. 433-443.

Hoek, E \& Bray, JW 1974, Rock Slope Engineering, The Institute of Mining and Metallurgy, London. 
Hoek, E, Carranza-Torres, C \& Corkum, B 2002, 'Hoek-Brown Failure Criterion - 2002 edition', in R Hammah (ed.), Proceedings of the 5th North American Rock Mechanics Symposium and the 17th Tunnelling Association of Canada Conference, University of Toronto Press, Toronto, pp. 267-273.

Hoek, E \& Diederichs, MS 2006, 'Empirical estimation of rock mass modulus', International Journal of Rock Mechanics and Mining Sciences, vol. 43, pp. 203-215.

Hoek, E, Kaiser, PK \& Bawden, WF 1995, Support of underground excavations in hard rock, Balkema, Rotterdam.

Itasca Consulting Group 2005, FLAC Fast Lagrangian Analysis of Continua, version 5, Itasca Consulting Group, Minneapolis.

Itasca Consulting Group 2018, 3DEC Three-Dimensional Distinct Element Code, version 5.2, Itasca Consulting Group, Minneapolis.

Karzulovic, A \& Read, J 2009, 'Rock Mass Model', in J Read \& P Stacey (eds), Guidelines for Open Pit Slope Design, CSIRO Publishing, Melbourne.

Khanmohammadi, S \& Hosseinitoudeshki, V 2014, 'The effect of water level on the stability of slopes', Journal of Novel Applied Sciences, vol. 3, no. 11, pp. 1237-1239.

Lorig, LJ 2009, 'Challenges in current slope stability analysis methods', in JR Reid (ed.), Proceedings of the Third International Symposium on Rock Slope Stability in Open Pit Mining and Civil Engineering, University de los Andes, Santiago.

Lorig, L, Stacey, P \& Read, J 2009, 'Slope Design Methods' in J Read \& P Stacey (eds), Guidelines for Open Pit Slope Design, CSIRO Publishing, Melbourne.

Mylvaganam, J, Baczynski, NRP, de Bruyn, IA \& Price, JR 2011, 'Distinct Element Analyses for Calibration of Rock Slope Properties', in E Eberhardt \& D Stead (eds), Proceedings of the 2011 International Symposium on Rock Slope Stability in Open Pit Mining and Civil Engineering, Canadian Institute of Mining, Metallurgy and Petroleum, Montreal.

Noorani, R, Ahangari, K \& Aloodari, S 2011, 'The Influence of Horizontal Stress on the Failure Mechanism and Slope Stability in ChadorMalu Iron Open Pit Mine', in E Eberhardt \& D Stead (eds), Proceedings of the 2011 International Symposium on Rock Slope Stability in Open Pit Mining and Civil Engineering, Canadian Institute of Mining, Metallurgy and Petroleum, Montreal.

Rose, ND, Scholz, M, Burden, King, M, Maggs, C \& Havaej, M 2018, 'Quantifying Transitional Rock Mass Disturbance in Open Pit Slopes Related to Mining Excavation', Proceedings of the 2018 International Symposium on Slope Stability in Open Pit Mining and Civil Engineering, Asociacion Nacional de Ingenieros de Minas and Colegio Oficial de Ingenieros de Minas del Sur, Seville.

Severin, J 2018, 'Importance of Characterization and Representation of Faults and Fault Damage Zones in Large Open Pit Slope Stability Models', Proceedings of the 2018 International Symposium on Slope Stability in Open Pit Mining and Civil Engineering, Asociacion Nacional de Ingenieros de Minas and Colegio Oficial de Ingenieros de Minas del Sur, Seville.

Smith, JV 2013, 'Interpreting local critical orientations of structural weakness in relation to stress and dilatancy in rock slopes', in PM Dight (ed.), Proceedings of the 2013 International Symposium on Slope Stability in Open Pit Mining and Civil Engineering, Australian Centre for Geomechanics, Perth, pp. 177-188.

Silva, R \& Gómez, P 2015, Towards a Mechanically Based Definition of the Disturbance Factor Using The "Slope Model" Lattice Code, IOS Press, Buenos Aires, pp. 3-10.

Sjöberg, J 2013, 'Numerical analysis, slope design and in situ stress', in PM Dight (ed.), Proceedings of the 2013 International Symposium on Slope Stability in Open Pit Mining and Civil Engineering, Australian Centre for Geomechanics, Perth, pp. 29-42.

Venter, J 2015, 'Probability of failure in open pit slope design', Proceedings of the 2015 International Symposium on Slope Stability in Open Pit Mining and Civil Engineering, South African Institute of Mining and Metallurgy, Johannesburg, pp. 413-422.

Wesseloo, J \& Read, J 2009, 'Acceptance Criteria', in J Read \& P Stacey (eds), Guidelines for Open Pit Slope Design, CSIRO Publishing, Melbourne.

Wines, DR 2016, 'A comparison of slope stability analyses in two and three dimensions', The Journal of The South African Institute of Mining and Metallurgy, vol. 116, no. 5, pp. 399-406. 
Understanding the sensitivity of numerical slope stability analyses

to geotechnical and other input parameters

DR Wines 